Reprod. Nutr. Dévelop., 1987, 27 (1 B), 287-288.

\title{
Effet du caséinomacropeptide (C.M.P.) sur la sécrétion gastrique et les taux circulants d'hormones digestives chez le veau préruminant
}

\author{
P. GUilloteau, J. A. CHAYVIALle $(*)$, F. Mendy $(* *)$, L. ROGeR $\left({ }^{* *}\right)$, \\ R. TOULLEC, C. BERNARD $\left({ }^{*}\right)$, A. MOUATS, P. FAVERDIN $\left({ }^{* * *}\right)$
}

Laboratoire du Jeune Ruminant, I.N.R.A., 65, rue de Saint-Brieuc, 35042 Rennes Cedex.

(*) I.N.S.E.R.M., U45, Hopital Edouard-Herriot, 69374 Lyon Cedex.

(**) Laboratoire SOPHARGA, 5, rue Bellini, 92806 Puteaux.

(***) Station de Recherches sur la Vache laitière, I.N.R.A., St-Gilles, 35590 L'Hermitage.

Summary. The intravenous injection of caseinomacropeptide (CMP) $(2.1 \mathrm{mg} / \mathrm{kg}$ live weight) did not inhibit gastric secretions or modify the plasma levels of digestive hormones in 15 to 18-week old preruminant calves. In our experimental conditions, this peptide did not seem to have an antigastrin action as suggested by Vasilevskaya et al. (1977).

Introduction. Le caséinomacropeptide (CMP) est un peptide (64 acides aminés) qui se forme dans l'estomac sous l'action des enzymes protéolytiques sur la caséine. Chez le veau préruminant, il passe très rapidement dans le duodénum. Chez le chien adulte, son administration par voie parentérale entraîne une inhibition très nette de la sécrétion de suc gastrique stimulée par l'ingestion d'un repas de viande ou l'injection d'histamine ou du pentapeptide $C$ terminal amidé de la gastrine (Vasilevskaya et al., 1977). Le but de notre travail était de vérifier cet effet inhibiteur chez le veau préruminant.

Matériel et méthodes. Trois veaux mâles de race Frisonne, âgés de 15 à 18 semaines, sont munis d'une poche abomasale innervée depuis 2 semaines et d'un cathéter placé dans une veine jugulaire externe. Ils ingèrent, en 2 repas/j distants de $7 \mathrm{~h}$, un lait de remplacement (48 à $53 \mathrm{~g}$ de matière sèche $/ \mathrm{kg} \mathrm{PV}^{0,75}$ ) dont les protéines ( $25 \%$ par rapport à la MS) sont apportées par un concentrat protéique de lactosérum dépourvu de CMP. Lors de chaque journée de mesures (7 par traitement), les veaux reçoivent $0,21 \mathrm{ml} / \mathrm{kg}$ de poids vif d'une solution contenant $9 \mathrm{~g} / \mathrm{l}$ de chlorure de sodium ou $10 \mathrm{~g} / \mathrm{l}$ de CMP, par perfusion dans la veine jugulaire pendant les 10 premières minutes postprandiales. Le suc gastrique est recueilli en totalité toutes les heures, depuis $1 \mathrm{~h}$ avant le repas jusqu'à $7 \mathrm{~h}$ après ; au milieu de chacune de ces périodes, du sang jugulaire est prélevé dans un tube contenant de l'héparine et de l'antiprotéase et le plasma est conservé pour le dosage des hormones digestives par radioimmunologie (gastrine, CCK, sécrétine, VIP, GIP, BPP, somatostatine, motiline). Dans cette présentation, nous ne détaillerons que les résultats concernant la gastrine.

Résultats et discussion. Le repas provoque une augmentation considérable des quantités d'ions $\mathrm{H}^{+}$sécrétés et des concentrations plasmatiques de gastrine pendant les 3 premières heures postprandiales (fig. 1) ; par rapport aux mesures effectuées à jeun, ces valeurs sont respectivement multipliées par 5,0 et 4,0 en moyenne $(P \leqslant 0,01)$, ce qui s'accorde avec les observations rapportées par Guilloteau et Toullec (1983) et Guilloteau et al. (1985). La corrélation des rangs de Spearman entre la concentration $\mathrm{d}^{\prime} \mathrm{H}^{+}$et celle de gastrine dans le plasma est significative $(r=0,48 ; P \leqslant 0,001)$; cette corrélation, qui ne tient pas compte des variations entre individus, est relativement élevée, ce qui est conforme aux 
observations généralement effectuées chez d'autres espèces. En revanche, l'infusion de CMP n'a aucun effet inhibiteur sur les sécrétions gastriques puisque la sécrétion d'ions $\mathrm{H}^{+}$est même accrue de $60 \%$ au cours de la troisième heure postprandiale. Elle n'a pas d'effet significatif sur l'évolution des taux circulants des hormones digestives dosées, mais les variations suivant les individus et les jours de prélèvements sont très importantes. Notons cependant que le taux de gastrine a tendance à être plus élevé $(18 \%$ en moyenne pendant les $7 \mathrm{~h}$ postprandiales), lors de la perfusion de CMP.
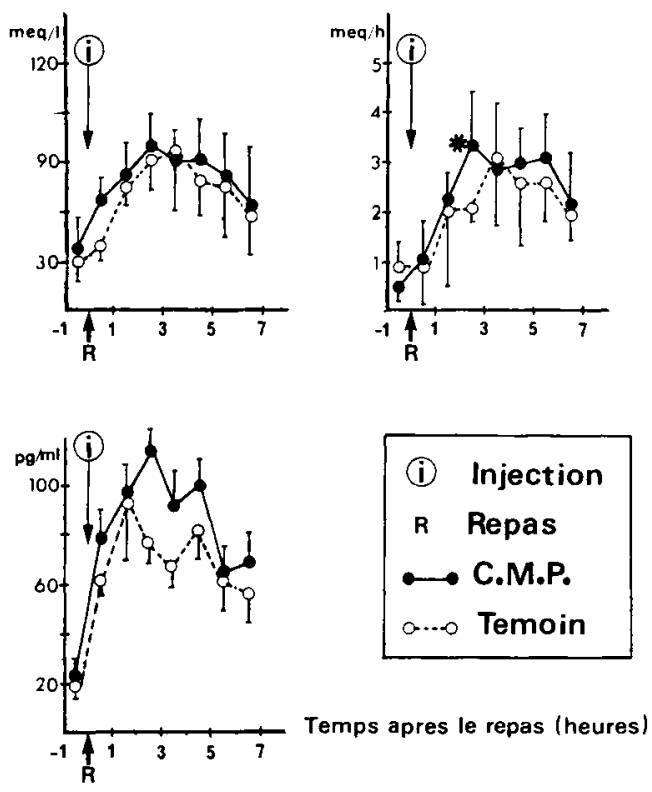

FIG. 1. - Evolution de la concentration et de la quantité d'ions $\mathrm{H}^{+}$sécrétés dans le suc gastrique et de la concentration plasmatique de gastrine en fonction du repas et du traitement (moyennes et écarts-types des moyennes). "Différence significative entre les 2 traitements $(P \leqslant 0,05)$.

En conclusion. Dans nos conditions expérimentales, l'injection intraveineuse de CMP n'inhibe pas la sécrétion gastrique et ne modifie pas les taux circulants des hormones digestives dosées. L'hypothèse d'un rôle antigastrine de type " hormones circulantes" ne semble pas être vérifiée pour ce peptide, chez le veau préruminant âgé de plusieurs mois.

Guilloteau P., Chayvialle J. A., Toullec R., Grongnet J. F., Dardillat C., 1985. Reprod. Nutr. Dévelop., 25, 780 .

Guilloteau P., Toullec R., 1983. Reprod. Nutr. Dévelop., 23, 967-977.

Vasilevskaya L. S., Stan E. Ya, Chernikov M. P., Shlyhin G. K., 1977. Vopr. Pitan., 4, 21-24. 